\title{
O USO DA TRANSAÇÃO NA SOLUÇÃO DE CONFLITOS DE NATUREZA TRIBUTÁRIA: PERSPECTIVAS ABERTAS PELA RESOLUÇÃO No 261, DE 11 DE SETEMBRO DE 2018, DO CONSELHO NACIONAL DE JUSTIÇA.
}

\author{
Rafael Carvalho da Rocha Lima*
}

\section{Resumo:}

O trabalho tem por objetivo investigar a aplicabilidade da transação tributária no direito brasileiro, mediante a análise das principais objeções habitualmente levantadas pela doutrina. A pesquisa orientou-se pelo método hipotético-dedutivo, mediante pesquisa bibliográfica e exame das normas jurídicas pertinentes, chegando-se a conclusão de que a transação tributária é compatível com o ordenamento jurídico pátrio, mas que sua utilização em maior escala depende da edição de leis por parte de cada ente tributante com enunciação critérios objetivos para solução do litígio tributário mediante acordo entre as partes.

Palavras-chave: Transação tributária; Interesse público; Discricionariedade; Acordo; Taxa de congestionamento.

\section{THE USE OF THE TRANSACTION IN SOLVING TAX NATURE CONFLICTS: PERSPECTIVES OPENED BY RESOLUTION Nº 261, OF SEPTEMBER 11, 2018, OF THE NATIONAL COUNCIL OF JUSTICE.}

\begin{abstract}
:
The work aims to investigate the applicability of the tax transaction in Brazilian law, by analyzing the main objections usually raised by the doctrine. The research was guided by the hypothetical-deductive method, through bibliographic research and examination of the relevant legal norms, reaching the conclusion that the tax transaction is compatible with the national legal system, but that its use on a larger scale depends on the edition of laws by each taxing entity with objective criteria for resolving the tax dispute by agreement between the parties.
\end{abstract}

Keywords: tax transaction; public interest; discretion; agreement; congestion charge

\section{INTRODUÇÃO}

A transação tributária no direito brasileiro há muito tempo tem gerado disputas e divergências na doutrina. O Código Tributário Nacional foi bastante sintético na disciplina desse assunto, reportando-se a necessidade de outra lei para regulamentar as hipóteses e requisitos de cabimento.

O princípio da indisponibilidade do interesse público, da legalidade estrita e da tipicidade do Direito Tributário erguem-se como argumentos relevantes para impedir a solução dos conflitos tributários por meios consensuais bilaterais como a transação. 
De toda forma, o crescente acúmulo de demandas no Poder Judiciário e as elevadas taxas de congestionamento de execuções fiscais despertaram a atenção do legislador para a necessidade de fomentar a autocomposição na esfera tributária.

A par das iniciativas do Conselho Nacional de Justiça (CNJ) no intuito de implementar uma política judiciária de solução adequada de conflitos, o Congresso Nacional, notadamente, a partir de 2015, aprovou uma série de leis no intuito de clarificar a possibilidade de a Administração Pública solucionar seus conflitos com particulares de forma amigável.

Embora a tentativa de aprovação de uma lei geral de transações tributárias não tenha alcançado êxito até o momento serviu para deflagrar um importante debate sobre os limites e possibilidades da transação tributária no direito brasileiro.

A Resolução $n^{\circ}$ 261/2018 do CNJ trouxe novamente à tona a necessidade de ampliar o uso da transação tributária enquanto mecanismo legítimo de equacionamento das contendas fiscais, possibilitando maior diálogo entre a Fazenda Pública e os contribuintes, além da solução mais eficiente dos conflitos com impactos positivos na arrecadação e efetivação de políticas públicas.

É necessário indagar se os princípios da legalidade estrita e da tipicidade tributária constituem obstáculos intransponíveis para utilização de maior escala da transação no direito tributário.

Por meio da revisão da literatura, da análise crítica dos entendimentos doutrinários e interpretação da legislação em vigor, procura-se investigar as características da transação tributária, sua natureza, requisitos e efeitos jurídicos à luz do ordenamento pátrio.

A revisão de antigos dogmas do direito tributário e a superação de alguns paradigmas permitirá que a transação tributária efetivamente alcance todo o seu potencial de equacionar disputas tributárias de forma célere, econômica e consensual com a consequente redução de demandas judiciais.

\section{A TRANSAÇÃO E OS MEIOS CONSENSUAIS DE SOLUÇÃO DE CONFLITOS 1.1 NATUREZA JURÍDICA}

A transação constitui espécie de negócio jurídico que tem por objetivo a solução de um conflito de interesses mediante concessões recíprocas dos envolvidos, resultando em acordo quanto aos direitos e obrigações de cada um. 


\section{O USO DA TRANSAÇÃO NA SOLUÇÃO DE CONFLITOS DE NATUREZA TRIBUTÁRIA: PERSPECTIVAS ABERTAS PELA RESOLUÇÃO № 261, DE 11 DE SETEMBRO DE 2018, \\ DO CONSELHO NACIONAL DE JUSTIÇA}

O Código Civil de 1916 incluía a transação entre os meios de extinção das obrigações e somente permitia a sua utilização quanto a direitos patrimoniais de caráter privado. Por sua vez, o Código Civil de 2012 trata da transação no título referente às várias espécies de contrato.

Nos dois códigos civis mencionados, consta que a transação opera-se mediante concessões mútuas dos interessados na prevenção ou extinção de um litígio, ou seja, de um conflito de interesses qualificado por uma pretensão resistida.

Conforme ressalta Sacha Calmon Navarro Coelho (2015, p. 744): “... a transação exige concessões recíprocas, como, v.g., renúncia a honorários. Se apenas uma parte cede, não há transação, senão que ato unilateral capaz de comover ou demover a outra parte.” Trata-se, portanto, de ato bilateral em que cada parte da relação jurídica dispõe de parte de sua pretensão.

Para Caio Mário da Silva Pereira (2017), a existência de dúvida quanto ao direito das partes constitui nota característica da transação, sendo que a incerteza pode ser de ordem subjetiva (percepção pessoal do interessado) ou objetiva, ou seja, "qualificação duvidosa do próprio direito".

Em síntese, a transação constitui acordo de vontades, permeado por concessões recíprocas, objetivando a composição entre as partes para solução consensual de um conflito entre elas havido.

$\mathrm{Na}$ doutrina civilista, prevalece o entendimento acerca da natureza contratual da transação, haja vista a exigência de concessões recíprocas e a possibilidade declarar, reconhecer ou modificar direitos e/ou obrigações.

No julgamento da medida cautelar na ação direta de inconstitucionalidade (ADIn) $n$. 2.405/RS, o Supremo Tribunal Federal entendeu que a transação não se confunde com benefício fiscal e por isso, não seria necessário o atendimento da exigência contida no art. 150, $\S 6^{\circ}$, da Constituição Federal.

Segundo Heleno Taveira Torres, a transação tributária não ostenta natureza contratual, porque o pacto da Administração tributária com o contribuinte diz respeito ao procedimento e não ao ato administrativo final de lançamento:

[...] nenhuma razão assiste aqueles que querem ver no ato decisional do procedimento uma espécie de 'contrato' entre o contribuinte e a Administração. Nada mais descabido. O que se verifica é tão-só a ponência no sistema jurídico de 
uma norma individual e concreta, típico ato administrativo, por meio do qual o contribuinte chega a um entendimento prévio com a Administração, participando do procedimento. Mais não será que espécie de ato preparatório ou de revisão de lançamento tributário previamente praticado. O modo lógico de alcançar a decisão, por aproximação consensual e bilateral, mediante concurso de vontade das partes, com mútuo sacrifício de expectativas, não desnatura o resultado, qualificando-o como espécie de ato negocial. (TORRES, 2003).

Em que pesem os fundamentos acima expostos, acredita-se que a transação tributária possui a natureza de contrato fiscal, podendo resultar na revisão de lançamento já praticado ou na expedição de lançamento segundo os termos validamente pactuados com o contribuinte.

A realização de transação no âmbito do direito privado há de respeitar os pressupostos de validade dos negócios jurídicos em geral, a saber: pessoas capazes, objeto lícito e forma prescrita ou não defesa em lei (art. 108 do Código Civil).

A existência de dúvida quanto aos direitos dos interessados também constitui um pressuposto da transação. Não por outra razão, o Código Civil atribui nulidade à transação "a respeito do litígio decidido por sentença passada em julgado, se dela não tinha ciência algum dos transatores, nos termos do art. 850."

Se houver certeza quanto ao direito aplicável não haverá lugar para transação, mas renúncia por parte do seu titular ou simples abstenção de seu exercício, o que poderá ensejar a prescrição da pretensão correlata.

No âmbito do direito privado prepondera a autonomia da vontade; cabe aos particulares decidir quanto ao grau das concessões recíprocas que estão dispostos a fazer para encerrar o conflito. Na esfera do direito público, apenas a lei pode dispor dos bens públicos por razões de interesse coletivo. O gestor público não pode, senão se a lei autorizar e nos limites nela previstos, abrir mão de receitas públicas, sob pena de responsabilidade civil, administrativa e criminal.

$\mathrm{Na}$ esfera do direito tributário, discute-se a necessidade de lei específica que autorize a transação com a tipificação das situações cabíveis e critérios para celebração. Outrossim, debate-se a possibilidade de a autoridade fiscal negociar sobre o montante do tributo devido, conceder descontos ou condições especiais de pagamento em virtude de incertezas sobre a existência ou aspecto quantitativo da obrigação ou, ainda, das condições pessoais do contribuinte e os custos da execução fiscal.

O art. 171 do Código Tributário Nacional - Lei $n^{\circ}$ 5.172, de 25 de outubro de 1966, trata da transação como uma das formas de extinção do crédito tributário, prevendo que a lei 


\section{O USO DA TRANSAÇÃO NA SOLUÇÃO DE CONFLITOS DE NATUREZA TRIBUTÁRIA: PERSPECTIVAS ABERTAS PELA RESOLUÇÃO № 261, DE 11 DE SETEMBRO DE 2018, \\ DO CONSELHO NACIONAL DE JUSTIÇA}

estabelecerá as condições para sua realização e indicará a autoridade competente para autorizá-la.

Outrossim, segundo a dicção legal em vigor, a caracterização da transação tributária exige concessões recíprocas e, por isso, não se confunde com atos unilaterais de renúncia ou de submissão à pretensão da parte contrária.

O CTN foi recepcionado na ordem constitucional vigente como lei complementar, haja vista o que estabelece o art. 146, III, da Constituição Federal. Dado o regime de federalismo fiscal instituído pela Lei Maior, entende-se que cada ente público pode disciplinar em lei própria a transação relativamente aos tributos de sua competência.

\subsection{ESTÍMULO AOS MEIOS ALTERNATIVOS DE SOLUÇÃO DE CONTROVÉRSIAS NA LEI 13.105/2015, NA LEI 13.140/2015 E NA RESOLUÇÃO CNJ N. 261/2018}

Em um dos seus "considerandos", a Resolução CNJ n. 261/2018 diz que suas regras guardam conformidade com os preceitos da Lei n. 13.105/2015 (CPC/2015), da Lei n. 13.140/2015 (Lei Nacional de Mediação) e da Lei 5.172/1966 (CTN).

De fato, a leitura do CPC/2015 deixa clara a intenção do legislador processual de fomentar os chamados meios consensuais de solução de controvérsias. Basta observar o que dizem os seus arts. $3^{\circ}, \S \S 2^{\circ}$ e $3^{\circ}, 165,168,175,334, \S \S 4^{\circ}$ e $8^{\circ}$, entre outros. Os dispositivos legais em comento ressaltam a importância da autocomposição e revelam a crença do legislador na capacidade das partes resolverem seus conflitos de forma amigável, especialmente com o auxílio de um terceiro facilitador (conciliador ou mediador).

Para incentivar a solução consensual dos conflitos, o CPC/2015 estabelece que, verificada a regularidade da petição inicial, o juiz, ato contínuo, deverá designar audiência de conciliação ou de mediação, a qual, somente não ocorrerá em duas hipóteses: $i$ ) se ambas as partes manifestarem, expressamente, desinteresse na composição consensual ou ii) quando não se admitir a autocomposição. Além disso, previu-se que o não comparecimento injustificado de qualquer das partes será considerado ato atentatório à dignidade da Justiça com a consequente aplicação de multa de até dois por cento da vantagem econômica pretendida ou do valor da causa (art. 334, $\S \S 4^{\circ}$ e $\left.8^{\circ}, \mathrm{CPC} / 2015\right)$.

O movimento em prol da consensualidade também se manifestou na aprovação da Lei n. 13.140, de 26 de junho de 2015, conhecida como Lei Nacional de Mediação, a qual deixa clara a possibilidade de a Administração Pública celebrar acordos com particulares ao 
prescrever em seu art. $3^{\circ}$ a viabilidade de a mediação versar sobre direitos disponíveis ou sobre "direitos indisponíveis que admitam transação". Sabe-se que, em matéria de direito público, não existe autonomia da vontade; os bens públicos e os direitos da coletividade não estão à disposição das autoridades administrativas, haja vista o princípio da indisponibilidade do interesse público. De toda forma, a lei pode autorizar, nos casos que estabelecer, a realização de autocomposição com os particulares, ou seja, a solução consensual de disputas entre administração e administrados.

O Capítulo II da Lei 13.140/2015 versa sobre a autocomposição de conflitos em que for parte pessoa jurídica de direito público. De acordo com o art. 32, que inaugura esse capítulo, União, Estados, Distrito Federal e Municípios poderão criar câmaras de prevenção e resolução administrativa de conflitos, no âmbito dos respectivos órgãos da Advocacia Pública com três competências: $i$ ) dirimir conflitos entre órgãos e entidades da administração pública; ii) no caso de controvérsia entre particular e pessoa jurídica de direito público, avaliar a admissibilidade dos pedidos de resolução de conflitos por autocomposição; iii) quando couber, promover a celebração de termo de ajustamento de conduta.

As transações tributárias, como regra, visam a composição entre pessoas jurídicas de direito público e devedores particulares (cidadãos e sociedades empresárias não integrantes da administração pública indireta). O art. 34 da Lei 13.140/2015 estabelece que a instauração de procedimento administrativo para resolução de conflito no âmbito da administração pública suspende a prescrição, mas o parágrafo segundo faz a seguinte ressalva: em se tratando de crédito tributário, a prescrição há de observar o disposto no CTN. E nem poderia ser diferente, por se tratar de matéria reservada à lei complementar, conforme inteligência da alínea "a" do inciso III do art. 146 da Constituição Federal.

No que interessa mais de perto ao objeto da presente investigação, o art. 38 da Lei Nacional de Mediação exclui as controvérsias jurídicas relativas a tributos administrados pela Secretaria da Receita Federal do Brasil ou a créditos inscritos em dívida ativa da União das regras previstas no incisos II e III do art. 32, ou seja, afasta tais litígios do âmbito das câmaras de prevenção e resolução administrativa de conflitos. Por alguma razão, o legislador entendeu por bem conferir tratamento diferenciado aos conflitos tributários.

De outro giro, os conflitos sobre tributos administrados pela Secretaria da Receita Federal ou créditos inscritos em dívida ativa da União envolvendo órgão ou entidades de direito público que integram a administração pública federal podem ser submetidos à 


\section{O USO DA TRANSAÇÃO NA SOLUÇÃO DE CONFLITOS DE NATUREZA TRIBUTÁRIA: PERSPECTIVAS ABERTAS PELA RESOLUÇÃO № 261, DE 11 DE SETEMBRO DE 2018, \\ DO CONSELHO NACIONAL DE JUSTIÇA}

composição extrajudicial pela Advocacia-Geral da União, mas a redução ou cancelamento do crédito dependerá de manifestação conjunta do Advogado-Geral da União e do Ministro de Estado da Fazenda, conforme alínea "b" do inciso III do art. 38 da Lei de Mediação. Isso demonstra maior zelo do legislador em relação aos créditos tributários em comparação com créditos de outra natureza, exigindo a manifestação conjunta dos dirigentes máximos da AGU e do Ministério da Fazenda em caso de redução ou cancelamento.

Ao instituir o Sistema de Solução Digital de Dívida Ativa, por meio da Resolução $n^{\circ}$ 261/2018, o Conselho Nacional de Justiça chama a atenção para a baixa eficiência do sistema de execução fiscal, bem como para o montante das dívidas ativas que terminam prescrevendo, caracterizando situação de remissão involuntária de créditos tributários e não tributários. Ao tempo em que revela sua preocupação com as taxas de congestionamento do Poder Judiciário, o efetivo recebimento dos créditos inscritos em dívida ativa e a disseminação da cultura da paz, a norma prevê a criação de grupos de trabalho interinstitucionais, com representantes do Poder Judiciário, do Ministério Público, da Advocacia Pública, da Administração Fazendária, dos Tribunais de Contas, das Defensorias Públicas e da Ordem dos Advogados do Brasil com vistas à identificação de processos passíveis de transação e elaboração de planilha de descontos, baseada em análise estatística e no índice de sucesso no recebimento dos créditos fiscais.

$\mathrm{O}$ art. $4^{\circ}$ da resolução em comento reporta-se ao art. 172 do CTN e ao art. 38 da Lei 13.140/2015 para destacar a necessidade de lei do respectivo ente federado para viabilizar a utilização do Sistema de Solução Digital da Dívida Ativa.

\section{ESPECIFICIDADES DA TRANSAÇÃO EM MATÉRIA TRIBUTÁRIA}

\subsection{PRINCÍPIOS ENVOLVIDOS}

A relação jurídico-tributária é regida pelo direito público, pois decorre do poderdever do Estado arrecadar tributos dos cidadãos com vistas à realização de atividades de interesse da coletividade (serviços públicos, exercício do poder de polícia, medidas de fomento etc.) Nesse caso, a atividade fiscal também orienta-se pelos princípios previstos no art. 37 da Constituição Federal, a saber: i) legalidade; ii) impessoalidade; iii) moralidade; iv) publicidade e v) eficiência, conforme o magistério de Onofre Alves Batista Júnior (2007, p. 317):

Rev. de Formas Consensuais de Solução de Conflitos | e-ISSN: 2525-9679 | Evento Virtual | v. 6 | 
As regras que disciplinam o procedimento de celebração de transações administrativo-tributárias, bem como os princípios que a iluminam, são normas do Direito Administrativo, tais como o princípio da eficiência administrativa, da impessoalidade, da legalidade, da moralidade, da razoabilidade, etc.

O princípio da legalidade é cardeal ao direito tributário no ordenamento pátrio. Em um Estado Democrático de Direito, o povo é titular do poder e, por isso, somente deve pagar os tributos com os quais haja consentido por meio de lei aprovada por seus representantes. Trata-se de garantia fundamental do contribuinte de que não sofrerá agressões indevidas ao direito de propriedade, vendando-se práticas confiscatórias. Por outro lado, não se pode confundir legalidade com legalismo. Conforme a pertinente crítica de Arnaldo Sampaio de Moraes Godoy (2009):

O modelo administrativo-fiscal atual esgota-se na própria seiva. Soluções bem comportadas, a exemplo de ampliação da máquina de cobrança e de uma maior dotação orçamentária para os órgãos de execução do crédito fiscal (entre eles o próprio Judiciário) a par de inexequíveis, mostram-se utópicas e imprestáveis.

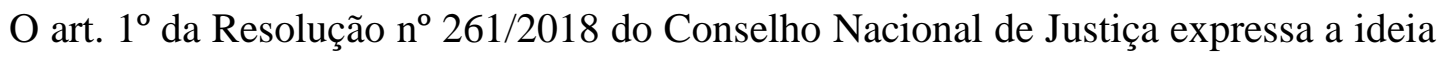
de que a composição entre o contribuinte e as Fazendas Públicas para solução de seus conflitos homenageia os princípios da eficiência e da razoável duração dos processos.

Com efeito, o princípio da eficiência, incluído no caput do art. 37 da Constituição Federal com a entrada em vigor da Emenda Constitucional no 19, de 04 de junho de 1998, é utilizado com frequência para justificar a utilização dos meios não adversariais de solução de conflitos.

Como regra, a solução negociada de um determinado conflito é mais célere se comparada com a heterocomposição promovida pelo Estado-Juiz no âmbito dos processos judiciais. O devido processo legal exige o cumprimento de uma série de formalidades e o pleno respeito ao contraditório e a ampla defesa, o que inclui a possibilidade de ampla produção probatória. Tudo isso somado às elevadas taxas de congestionamento de processos no Poder Judiciário termina por retardar além do razoável a entrega da prestação jurisdicional.

$\mathrm{Na}$ autocomposição, as partes envolvidas no conflito constroem a solução que lhes pareça razoável sem maiores formalidades. Por vezes, dispensam a dilação probatória e chegam a um consenso à despeito de inexistência de clareza quanto aos fatos e ao direito 


\section{O USO DA TRANSAÇÃO NA SOLUÇÃO DE CONFLITOS DE NATUREZA TRIBUTÁRIA: PERSPECTIVAS ABERTAS PELA RESOLUÇÃO № 261, DE 11 DE SETEMBRO DE 2018, \\ DO CONSELHO NACIONAL DE JUSTIÇA}

aplicável. Chega-se ao acordo com menor dispêndio de tempo, porque as partes coordenam esforços em busca de uma solução satisfatória para o seu problema.

O excesso de processos judiciais em matéria tributária, os custos sociais e econômicos envolvidos na condução de tais processos e os baixos índices de recebimento de créditos pela via da execução fiscal são fatores frequentemente lembrados como motivos relevantes para utilização transação tributária. Daí a pertinência dos princípios da eficiência, da economicidade e da razoável duração de processos relativamente à transação tributária.

O inciso IV do art. $2^{\circ}$ da Resolução CNJ no 261/2018 reporta-se aos princípios da moralidade, da probidade administrativa e do interesse público. A solução consensual dos conflitos tributários não pode servir de instrumento para favorecimentos, via para obtenção de vantagens ilícitas por determinados contribuintes ou mecanismo de dano ao erário. É preciso compatibilizar o interesse público na arrecadação de tributos com o direito do contribuinte a ser tributado nos estritos limites da legalidade, segundo a sua capacidade contributiva.

O principal motivo para transação em matéria tributária é a racionalização do processo de cobrança dos créditos dessa natureza, evitando-se a eternização de disputas e o prolongamento de processos judiciais cujos custos superem o proveito econômico que eles sejam capazes de oferecer. Para Rayneider Brunelli Oliveira Fernandes (2015), a busca da consensualidade no processo tributário é um meio de se alcançar a eficiência na atividade arrecadatória.

Na esteira do Projeto de Lei $n^{\circ} 5.082 / 2009$ em trâmite no Congresso Nacional, mas independentemente da aprovação de uma lei geral de transações, entende-se que os princípios enunciados no art. $2^{\circ}$ da Lei $n^{\circ}$ 9.784/1999 também hão de ser observados em qualquer tipo de acordo entre Administração Pública e particulares. Na tributação praticada em Estados democráticos não deve haver espaço para abusos, negociatas, interesses escusos ou desvios de finalidade.

\subsection{PECULIARIDADES DO LITÍGIO TRIBUTÁRIO, FORMAS, LIMITES, POSSIBILIDADES E EFEITOS DA TRANSAÇÃO TRIBUTÁRIA}

A despeito de a transação estar prevista no CTN como forma de extinção do crédito tributário, a doutrina ainda debate a sua efetiva viabilidade frente ao ordenamento jurídico vigente e o momento em que seria possível em relação ao nascimento do crédito tributário.

Rev. de Formas Consensuais de Solução de Conflitos | e-ISSN: 2525-9679 | Evento Virtual | v. 6 | 
Para muitos, a transação não seria possível para prevenir litígios, mas apenas para resolver aqueles já instalados, mesmo que antes do debate ser levado ao Poder Judiciário. Luis Eduardo Shoueri (2018) entende que a transação tributária não se presta à prevenção de litígios na medida em que a eliminação do conflito pressuporia o prévio lançamento, condição para a definição e quantificação do pretensão do Fisco. Em posição oposta, merece registro a tese de Maria Tereza Soares Lopes (2018) quanto a aptidão da transação para prevenir litígios:

[...] é plenamente defensável a transação em matéria tributária, desde que haja regulamentação legal e autorização, o que possibilita delegar a um terceiro imparcial, árbitro ou mediador, a solução de controvérsias relativas a créditos tributários, mesmo em momento anterior à formação do litígio, por ser medida capaz de ampliar o acesso à justiça e promover segurança jurídica.

A questão pode ser formulada de outra forma: é possível celebrar transação antes da realização do lançamento tributário? De acordo com o art. 142 do CTN, o lançamento é o procedimento administrativo voltado à verificação do fato gerador, à identificação do sujeito passivo e ao cálculo do tributo devido. Uma corrente de pensamento defende que o lançamento constitui o crédito tributário, mas corrente contrária sustenta que o crédito nasce juntamente com a obrigação tributária, no momento do fato gerador. (COELHO, 2015, p. 664). Seria possível a transação antes do acontecimento do fato gerador? A resposta é negativa. Antes da concretização do fato imponível não há conflito, quando muito, divergência de interpretações da lei em tese, o que é insuficiente para caracterização do litígio. Por outro lado, o litígio pode residir justamente na ocorrência ou não do fato gerador.

Entende-se que a instauração do conflito em sede administrativa, por ocasião da impugnação do lançamento, já tornaria possível o uso da transação, ou seja, não é necessária a formalização de uma demanda judicial para a utilização desta modalidade de extinção do crédito tributário. Em outras palavras, é possível falar em transação tributária em âmbito extrajudicial, ou seja, a transação pode ter por objeto créditos "não ajuizados".

Questão relevante diz respeito à possibilidade ou não de uma lei geral de transações em matéria tributária. Luis Eduardo Schoueri posta-se contra a validade de uma lei geral de transações, tendo em vista o caráter compulsório dos tributos e os riscos de aumento da judicialização, devendo a lei estabelecer a matéria litigiosa passível de transação e as condições correspondentes. Nas palavras do eminente jurista "para cada situação, o legislador deverá disciplinar os termos da transação." (SCHOUERI, 2018). 


\section{O USO DA TRANSAÇÃO NA SOLUÇÃO DE CONFLITOS DE NATUREZA TRIBUTÁRIA: PERSPECTIVAS ABERTAS PELA RESOLUÇÃO № 261, DE 11 DE SETEMBRO DE 2018, \\ DO CONSELHO NACIONAL DE JUSTIÇA}

De seu turno, Lucas Bevilacqua e Leonardo Buíssa (2015), a partir da leitura do $\S 6^{\circ}$ do art. 150 da Constituição Federal, entendem que a transação há de ser autorizada em lei específica a bem da transparência fiscal. Nada obstante, considera-se que a lei instituidora de determinada espécie tributária pode estabelecer situações em que a transação é possível. Outrossim, não se vislumbra óbice para uma lei geral de transações com critérios abrangentes para disciplina dessa forma especial de extinção do crédito tributário, relacionada a situações de difícil recuperação com considerações sobre o custo-benefício da cobrança judicial e/ou administrativa.

Heleno Taveira Torres (2003) vê na interpretação de enunciados normativos tributários complexos, na aplicação de conceitos jurídicos indeterminados e na existência de dúvida quanto à ocorrência do fato gerador campo fértil para tentativa de solução consensual dos conflitos. De fato, nessas situações, contribuinte e Administração Tributária podem compor suas divergências por meio da transação. O desafio está em assegurar a isonomia, a fim que todos os contribuintes em idêntica situação recebam o mesmo tratamento do Fisco.

Nos termos do art. 141 do CTN, o crédito tributário regularmente constituído somente se modifica ou extingue nos casos previstos nesta lei. A partir da leitura desse dispositivo legal, Sacha Calmon Navarro Coêlho (2015, p. 668) infere os seguintes princípios: i) moralidade dos atos administrativos; $i$ ) vinculação à lei (legalidade) e iii) indisponibilidade dos bens e receitas do Estado por parte de seus agentes. O exercício da autotutela permitirá a retificação do lançamento nas hipóteses de erro (arts. 145 e 149 do CTN). Ora, diante da impugnação do contribuinte ao lançamento, a Administração Tributária pode concordar com parte das alegações daquele e, por meio da transação, comprometer-se a rever em parte um ou mais lançamentos, mediante, por exemplo, o reconhecimento por parte do contribuinte da legitimidade de uma fração do crédito (concessões recíprocas).

Como visto, a transação tributária é uma das modalidades de extinção do crédito tributário previstas no próprio CTN. Seria ela diferente da transação em outras searas do direito público? Acredita-se que não. A disposição de bens e receitas públicas há de ser autorizada em lei, seja o crédito de origem tributária ou não. Em todos os casos, a Administração deve perseguir a isonomia, oferecendo a mesma proposta de acordo aos cidadãos em igual situação, ou seja, envoltos no mesmo problema de aplicação do direito em determinada espécie de relação jurídica.

Rev. de Formas Consensuais de Solução de Conflitos | e-ISSN: 2525-9679 | Evento Virtual | v. 6 | 
Ao transigir com o contribuinte, a Administração Tributária poderá conceder parcelamento, elastecer o prazo para pagamento, perdoar parte da dívida e até eximir o contribuinte de determinada penalidade, desde que a lei o permita para o alcance de uma finalidade pública como, por exemplo, a satisfação de créditos de difícil recebimento de forma mais célere e com economia dos custos de cobrança.

Ao comentar a (in)disponibilidade do crédito tributário, Maria Tereza Soares Lopes (2018, p. 100) observa que ele: “... constitui direito patrimonial do Fisco que comporta transação, renúncia, anistia, remissão e parcelamento, conforme preceituam os artigos 151, 156, 171 e 180 do CTN, tendo, portanto, parcela de disponibilidade."

Quando o parcelamento, a moratória, a remissão parcial e/ou a anistia depender de alguma concessão por parte do contribuinte, como por exemplo, a desistência da ação em que discuta a existência ou o valor do crédito tributário tem-se por configurada a transação. $\mathrm{Na}$ mesma direção, manifestou-se Hugo de Brito Machado Segundo (2017):

\footnotetext{
A rigor, o favor fiscal de que cuida a Lei $\mathrm{n}^{\circ}$ 9.779/99, assim como outros semelhantes (v. g., REFIS), que reclamam a desistência de ações judiciais por parte do contribuinte, em troca de condições mais favoráveis para o pagamento do tributo, não configuram apenas anistia, visto que não ensejam apenas a redução ou a exclusão das multas. Implicam também redução do principal, pelo que são, também, remissão parcial. E ainda ensejam o pagamento em prazos mais elásticos, assumindo a forma de moratória/parcelamento. Por isso, não obstante o entendimento contrário do STJ, data venia, nos parece correta a tese segundo a qual se trata de transação. Afinal, por meio de transações mútuas as partes põem fim a um litígio.
}

Luis Eduardo Schoueri (2018) comunga do mesmo entendimento, identificando no "programa de parcelamento Refis" uma forma de transação, diante da oportunidade de recolhimento de tributos com excepcional redução de encargos, mediante a desistência das ações por meio das quais os contribuintes discutiam a validade das exações.

Em outras palavras, a transação pode implicar ou envolver uma das outras modalidades ou espécies de extinção ou suspensão do crédito tributário (mas não todos elas) em contrapartida a uma concessão da parte adversa (contribuinte ou responsável), conforme precisa lição de Nadja Araújo (2006):

A exigência de expressa admissão no ordenamento tributário positivado de um dado meio para extinção creditícia requer a distinção (dogmática) entre cada uma das categorias arroladas no art. 156 do CTN, mormente em face da transação.

A particularidade desta transação é ser um acordo entre as partes, uma acomodação das pretensões litigiosas com vistas à extinção do crédito por um dos meios adotados 
no direito tributário e compatível com a espécie, resultando na extinção do processo conformador do caso. Assim, ajusta-se a finalização do crédito por pagamento, dação em pagamento, compensação, remissão.

A prescrição e a decadência são categorias moldadas pela lei tributária, sendo inválido e ineficaz um acordo acerca do tema.

Direcionar a solução do litígio para uma decisão administrativa ou judicial é renunciar à transação, sendo, portanto, inconciliáveis o art. 171 e o art. 156, IX, X, do CTN.

O pagamento imediato pelo contribuinte (em troca de remissão parcial sobre o crédito litigioso) surge como o resultado mais esperado da transação com base no art. 171, da Lei Tributária Nacional.

A hipótese de anistia prevista na alínea "d" do inciso II do art. 181 do CTN de certo modo enquadra-se no conceito de transação. Afinal, a Administração, autorizada por lei, perdoa a penalidade pecuniária em troca do recolhimento do tributo no prazo fixado.

Como regra, uma vez firmada a transação e cumpridas as obrigações de cada parte (contribuinte e Administração tributária), ela deve ser considerada perfeita e acabada com a consequente extinção do crédito tributário. No entanto, se ficar provado algum vício de vontade ou situação de dolo, fraude ou simulação, será possível anular o acordo, respeitado o direito ao contraditório e a ampla defesa, restabelecendo-se a exigibilidade do crédito pelo seu valor integral. De qualquer forma, será possível o abatimento de eventuais parcelas pagas, sob pena de enriquecimento sem causa.

Convém refletir sobre a conveniência de se restringir a possibilidade de transação à dispensa de juros, multas, encargos de sucumbência e demais encargos pecuniários, permitindo "descontos" sobre o montante principal apenas em situações excepcionais a exemplo do que fez o Projeto de Lei $n^{\circ} 5.082 / 2009$. A intenção da regra parece ser a de evitar o aviltamento do crédito tributário em benefício dos que descumprem a lei tributária, mas em alguns casos poderá inviabilizar o recebimento de qualquer valor, implicando "remissão involuntária".

\section{3 É POSSÍVEL EXIGIR A RENÚNCIA A DISCUSSÕES JUDICIAIS E/OU} ADMINISTRATIVAS?

É bastante comum nos diplomas legais que versam sobre transação com a Administração Pública a previsão de regras no sentido e que, em caso de acordo em conflito objeto de demanda judicial, o particular deve renunciar ao direito sob o qual se funda a ação para nada mais reclamar a tal título com a consequente extinção do processo com exame de mérito, na forma do art. 487, III, "b”, do CPC. 
Não se divisa qualquer vício na exigência de renúncia ao direito que fundamenta a ação, pois o acordo serve para terminar o litígio outrora havido entre as partes. Nesse caso, não seria lícito ao particular anuir com determinada proposta de transação, obtendo a vantagem correlata para, em momento posterior, retomar sua tese de defesa em prejuízo à pacificação social e a boa-fé objetiva.

A transação impede a atuação heterocompositiva do juiz ou do árbitro; é a forma pela qual os próprios titulares dos direitos em disputa resolvem suas desavenças de forma consensual e, por isso, fala-se em autocomposição. A revisão do acordo pelo Judiciário, em princípio, somente poderia se dar nos casos de vício de vontade, por dolo, fraude ou corrupção.

\section{OBJEÇÕES LEVANTADAS CONTRA A TRANSAÇÃO TRIBUTÁRIA}

De acordo com o art. $3^{\circ}$ do CTN, o tributo constitui prestação pecuniária compulsória e sua cobrança é feita mediante atividade administrativa plenamente vinculada. Em reforço, o parágrafo único do art. 142 do mesmo código estatui que a atividade administrativa de lançamento é vinculada e obrigatória, sob pena de responsabilidade funcional.

Nesse contexto, é preciso examinar se a transação tributária, ao possibilitar a redução do montante devido seja a título de tributo seja a título de penalidade, não encontraria óbice aos preceitos legais em comento.

Importa salientar que o próprio CTN prevê que a transação tributária constitui uma das hipóteses de extinção do crédito tributário. Como não podem existir regras incompatíveis em um mesmo código, por definição um conjunto de normas dotado de afinidade temática e harmonia, é necessário um esforço de compatibilização.

A razão está com Maria Tereza Soares Lopes ao considerar, com base na lição de Priscila Faricelli Mendonça, que o dever de arrecadar tributos não implica indisponibilidade absoluta do crédito tributário:

[...] o que é indisponível, de fato, é a atividade de cobrança do crédito tributário, e não o crédito tributário por si, pois o administrador não pode abandonar a função de lançar, arrecadar e fiscalizar o tributo, sob pena de desvio desta. Outrossim, a competência tributária constitucionalmente outorgada é indisponível mais isso não significa dizer o mesmo do crédito tributário. (LOPES, 2018, p. 101) 


\section{O USO DA TRANSAÇÃO NA SOLUÇÃO DE CONFLITOS DE NATUREZA TRIBUTÁRIA: PERSPECTIVAS ABERTAS PELA RESOLUÇÃO № 261, DE 11 DE SETEMBRO DE 2018, \\ DO CONSELHO NACIONAL DE JUSTIÇA}

De fato, cabe ao legislador ponderar os princípios da isonomia, da indisponibilidade relativa do crédito público e da eficiência para demarcar as situações em que a transação é autorizada, ainda que isso implique a remissão parcial de créditos tributários, a fim de assegurar o ingresso de recursos nos cofres públicos com o menor dispêndio possível.

Ao contrário do que sustentam alguns, a transação tributária é perfeitamente compatível com o princípio da indisponibilidade do interesse público, porque este não significa que a Administração tributária sempre esteja correta nem que o Poder Judiciário seja via de curso forçado.

Com efeito, a prática jurídica e a jurisprudência dos Tribunais demonstra que, não raras vezes, a Fazenda Pública equivoca-se na interpretação e aplicação da lei tributária, levando o contribuinte ao Poder Judiciário para obstar cobranças indevidas ou mesmo para assegurar o respeito ao devido processo legal.

Por vezes, a necessidade de arrecadação decorrente das crescentes demandas sociais por serviços públicos mais abrangentes e de qualidade ou mesmo uma visão absolutista de Estado, refratária ao diálogo com o contribuinte, faz com que a Administração tributária adote determinada interpretação da lei que se mostra incompatível com a Constituição, levando à judicialização em massa de determinadas controvérsias.

Outrossim, devido ao princípio da presunção de constitucionalidade das leis, em muitos casos a Administração tributária vê-se forçada a lançar tributos mesmo diante da impugnação dos contribuintes fundada em contrariedade à Constituição, pela impossibilidade de reconhecimento da inconstitucionalidade da exação na via administrativa. Nesse sentido, a súmula $\mathrm{n}^{\circ} 2$ do Conselho Administrativo de Recursos Fiscais preconiza que: "O CARF não é competente para se pronunciar sobre a inconstitucionalidade de lei tributária”.

Com a melhoria do nível de acesso ao Poder Judiciário, inúmeros contribuintes recorrem à Justiça com demandas antiexacionais para se verem livres de cobranças de tributos inconstitucionais, acarretando relevante acúmulo de processos, o aumento das taxas de congestionamento e significativas despesas com a defesa da Fazenda Pública em juízo.

Ora, quando o Fisco antevê com alguma margem de segurança que a tese dos contribuintes encontrará guarida no Poder Judiciário, a transação exsurge como medida salutar e recomendada, evitando-se a oneração do Estado com as despesas de acompanhamento processual, restituição de custas adiantadas e honorários advocatícios. 
Heleno Torres (2003) também defende a tese da compatibilidade entre a transação e a indisponibilidade do interesse público, sustentando que o crédito tributário é disponível nos termos do que vier a prever a lei, enquanto expressão da vontade popular.

O fato é que não existe apenas um interesse público correspondente ao recolhimento integral dos tributos devidos por todos contribuintes. Além de receber seus créditos, a Administração deve zelar pela supremacia da Constituição, pelo estabelecimento de diálogo com os cidadãos para solução amigável de conflitos, pela uso racional da máquina judiciária, pela eficiência na administração tributária etc. Em síntese, para muitos casos, a transação será a melhor forma de alcançar o interesse público.

A tipicidade característica do Direito Tributário visa a conferir segurança jurídica aos contribuintes, impedindo a cobrança de tributos fora das hipóteses de incidência rigorosamente descritas em lei. Ocorre que a tipicidade não é capaz, por si só, de eliminar toda e qualquer margem de apreciação dos fatos pela autoridade fiscal. Ademais, devido a complexidade do sistema tributário e as naturais divergências interpretativas, não raro, surgem dúvidas no momento da aplicação do direito tributário, o que abre espaço a algum grau de discricionariedade aos destinatários da norma, conforme esclarece Rayneider Brunelli (2015):

\footnotetext{
Em suma, o fechamento operativo do tipo pode servir à segurança jurídica, mas a discricionariedade (no caso específico da transação) surge quando já está instalada a insegurança (o conflito judicial ou administrativo, arrastando-se excessivamente no tempo). Desta maneira, ainda que se cobice expulsar a incerteza pela tipificação precisa (o antecedente), a realidade fática (o consequente) pode descompassar dela, até porque também existem os conceitos indeterminados e as cláusulas gerais na regra matriz.
}

As leis específicas que autorizam a realização de transações tributárias devem estabelecer critérios objetivos, ou seja, descrever os requisitos a serem preenchidos em dada situação concreta para a extinção do crédito tributário.

A partir do momento em que o legislador, fundamentado em criteriosa manifestação dos órgãos de consultoria jurídica, identifica situações de cobrança indevida ou de validade jurídica duvidosa, descreve na norma autorizativa da transação as hipóteses em que ela pode ocorrer, com a especificação do grupo de contribuintes, da espécie de tributo, do período de ocorrência do fato gerador e demais pormenores da relação jurídica tributária controvertida, a margem de discricionariedade da Administração Tributária torna-se praticamente nula. 


\section{O USO DA TRANSAÇÃO NA SOLUÇÃO DE CONFLITOS DE NATUREZA TRIBUTÁRIA: PERSPECTIVAS ABERTAS PELA RESOLUÇÃO № 261, DE 11 DE SETEMBRO DE 2018, \\ DO CONSELHO NACIONAL DE JUSTIÇA}

Aliomar Baleeiro ( 2015, p. 1330) comunga do entendimento de que eventual discricionariedade depende do que estabelecer a lei autorizativa: "A autoridade só pode celebrá-la, com relativo discricionarismo administrativo na apreciação das condições, conveniências e oportunidades, se a lei lho faculta e dentro dos limimtes e requisitos por ela fixados".

A discricionariedade nem sempre constitui algo negativo. $O$ legislador tem dificuldades em prever com riqueza de detalhes todas as situações e requisitos para realização da transação. Há uma tendência cada vez maior na utilização de conceitos jurídicos indeterminados e fórmulas mais abertas, a fim de que os agentes encarregados da gestão pública tenham melhores condições de dar respostas adequadas às novas demandas sociais. É preciso buscar um equilíbrio entre segurança e praticabilidade.

A transação tributária não parece estar sujeita a maiores níveis de corrupção de que qualquer outro tipo de relação jurídica entre a Administração Pública e particulares. O direito público oferece diversos mecanismos de controle para prevenir e combater a corrupção. Além dos mecanismos de controle interno de cada órgão (procuradorias, controladorias, corregedorias, ouvidorias etc), existem órgãos de controle externo como os Tribunais de Contas e o Ministério Público devidamente estruturados e capacitados para agir em defesa da legalidade.

Ao autorizar a transação tributária, o legislador deve, na medida do possível, evitar que os sonegadores mal intencionados recebam remissões e anistias injustificáveis. É preciso aperfeiçoar os mecanismos de inteligências fiscal para identificar situações de fraude e ocultação de bens.

Com algumas cautelas, o legislador e a Administração tributária podem mitigar o risco de utilização indevida da transação por pessoas desmerecedoras de qualquer "favor fiscal".

\section{CONCLUSÃO}

A transação tributária constitui instituto jurídico compatível com o ordenamento jurídico pátrio, mas, na prática, está longe de alcançar todo o potencial que apresenta para solução eficiente dos litígios entre a Fazenda Pública e os contribuintes, haja vista a compreensão restritiva adotada pelas autoridades fazendárias. 
O princípio da indisponibilidade do interesse público não impede a extinção de créditos tributários por transação, pois a lei, ao perseguir objetivos constitucionais como a razoável duração de processos e a eficiência administrativa, pode autorizar a autocomposição na seara tributária.

A ausência de discricionariedade dos agentes fiscais na cobrança de tributos não interdita a solução consensual dos conflitos tributários mediante transação. Além das falhas existentes na própria legislação, as autoridades administrativas também incorrem em equívocos no lançamento de tributos, na interpretação da regra matriz e na aplicação de penalidades.

Em situações de dúvida quanto à ocorrência do fato gerador ou relacionadas ao aspecto quantitativo da obrigação tributária - incertezas quanto a base de cálculo ou alíquota aplicável - há espaço para concessões recíprocas entre contribuinte a Administração tributária a ser demarcado em lei com vistas à composição não adversarial do conflito.

Ao lado do interesse público na arrecadação integral dos tributos instituídos por lei com base na competência outorgada a cada ente pela Constituição, existem outros interesses públicos relevantes como o bom funcionamento do Poder Judiciário, a solução eficiente dos conflitos, o estabelecimento de uma relação dialogal entre cidadão e Fazenda Pública, na recuperação de créditos de difícil recebimento etc.

Os riscos de desvio de conduta na realização de transações tributárias não devem inibir a sua utilização, mas fomentar mecanismos de controle, prevenção e combate à corrupção.

O legislador deve buscar o equilíbrio entre segurança e eficiência, fornecendo meios à Administração tributária para solucionar de forma amigável boa parte de seus litígios e relegando a cobrança judicial para situações em que a autocomposição não for possível.

A Resolução nº 261/2018 do CNJ, na esteira do Código de Processo Civil de 2015 e da Lei 13.140/2015 - Lei Nacional de Mediação, visa fomentar a autocomposição entre o contribuinte e as Fazendas Públicas com o estabelecimento de critérios objetivos a partir de dados estatísticos e classificação de créditos, conciliando os princípios da eficiência e da moralidade administrativa.

É preciso superar antigos dogmas para que a Administração Tributária possa avançar na utilização de mecanismos de solução consensual de conflitos como a transação e colher os inúmeros benefícios daí advindos em termos de arrecadação, eficiência e pacificação social. 


\section{REFERÊNCIAS}

ARAÚJO, Nadja. (In) Disponibilidade dos Tributos e os Meios de Solução dos Litígios. Interesse Público - IP, Belo Horizonte, ano 8, n. 35, jan./fev. 2006. Disponível em: <http://www.bidforum.com.br/bid/PDI0006.aspx?pdiCntd=49319>. Acesso em: 17 jul. 2019

BALEEIRO, Aliomar. Direito Tributário Brasileiro. 13. ed. atualizada por Misabel Abreu Machado Derzi. Rio de Janeiro: Forense, 2015.

BATISTA JÚNIOR, Onofre Alves. Transações administrativas: um contributo ao estudo do contrato administrativo como mecanismo de prevenção e terminação de litígios e como alternativa à atuação administrativa autoritária, no contexto de uma administração pública mais democrática. São Paulo: Quartier Latin, 2007, p. 317

BUÍSSA, Leonardo; BEVILACQUA, Lucas. Consensualidade na Administração Pública e transação tributária. Fórum Administrativo - FA, Belo Horizonte, ano 15, n. 174, p. 46-54, ago. 2015.

COÊLHO, Sacha Calmon Navarro. Curso de Direito Tributário Brasileiro. 14ª ed., Rio de Janeiro: Forense, 2015.

GODOY, Arnaldo Sampaio de Moraes. Transação tributária: contexto, texto e argumentos. Revista Fórum de Direito Tributário RFDT, Belo Horizonte, ano 7, n. 39, maio/jun. 2009. Disponível em:

<http://www.bidforum.com.br/bid/PDI0006.aspx?pdiCntd=57666>. Acesso em: 17 jul. 2019.

FERNANDES, Rayneider Brunelli Oliveira. A transação tributária a serviços da consensualidade e da eficiência administrativa: aspectos polêmicos sobre a viabilidade da transação tributária em face dos princípios constitucionais do Direito Administrativo. Revista da Faculdade de Direito da UERJ - RFD, n. 27, 2015.

LOPES, Maria Tereza Soares. Arbitragem e mediação no poder público: breve análise da permissibilidade na seara constitucional tributária. Revista de Formas Consensuais de Solução de Conflitos, Porto Alegre, v. 4, n. 2, p. 88-106, jul./dez. 2018.

PEREIRA, Caio Mário da Silva Pereira. Instituições de direito civil - vol. III. Atual. Caitlin Mulholland. 21. ed. Rio de Janeiro: Forense, 2017. E-book.

SEGUNDO, Hugo de Brito Machado. Código Tributário Nacional: anotações à Constituição, ao Código Tributário Nacional e às Leis Complementares 87/1996 e 116/2003. 6. ed. rev., atual. e ampl. São Paulo: Atlas, 2017.

SCHOUERI, Luís Eduardo. Direito tributário. 8. ed. São Paulo: Saraiva Educação, 2018. Ebook. 
TORRES, Heleno Taveira. Transação, Arbitragem e Conciliação Judicial como Medidas Alternativas para Resolução de conflitos entre Administração e Contribuintes - Simplificação e Eficiência Administrativa. Revista Fórum de Direito Tributário - RFDT, Belo Horizonte, ano 1, n . 2, mar./abr. 2003. Disponível em:

<http://www.bidforum.com.br/bid/PDI0006.aspx?pdiCntd=12926>. Acesso em: 17 jul. 2019 